\title{
O Crew Resource Management como Contributo da Ciência Aeronáutica para a Ciência Médica
}

\author{
Crew Resource Management and Aircraft Science as a Contribution
for Medical Science
}

Armindo MARTINS

Acta Med Port 2014 Nov-Dec;27(6):681-684

Palavras-chave: Conhecimentos, Atitudes e Prática em Saúde; Equipa de Assistência ao Paciente; Melhoria de Qualidade.

Keywords: Health Knowledge, Attitudes, Practice; Patient Care Team; Quality Improvement.

\section{Introdução ao Crew Resource Management}

Para se entender o Crew Resource Management (CRM) é importante perceber que esta disciplina decorre da necessidade de um melhor entendimento dos acidentes. A introdução das caixas negras nos aviões expôs a indisciplina de procedimentos como principal razão de acidentes, seguida de uma deficiente consciência situacional em tempo útil, que falseia a análise de risco com consequências ao nível do processo da tomada de decisão. Ou seja, os acidentes acontecem, no essencial, em resultado de aspetos de origem comportamental, e não por falhas técnicas.

A estatística demonstra que, em cada quatro acidentes, três ocorrem com o avião sem anomalias - devido a 'erro do piloto' ou por razões que poderiam ter sido evitadas. Neste âmbito, o CRM aparece como ferramenta privilegiada, proporcionando acções de Refrescamento, Treino e Avaliação, tanto em ambiente de sala de aula como simulador ou avião.

Estes aspetos comportamentais tanto são aplicáveis em ambiente de tripulação aérea, como em ambiente de equipa médica. Por entre os fatores humanos sublinharia, entre muitos outros, a disciplina de procedimentos, liderança, trabalho em equipa, análise de risco e tomada de decisão, gestão de stress, da fadiga, da carga de trabalho, do estilo de vida versus a gestão do descanso, comunicação e crítica, gestão do conflito, disciplina e rigor, cultura de reporte voluntário e a gestão do erro individual e organizacional, a aceitação do erro por rotina e as condições latentes e a complacência. ${ }^{1}$

\section{Cultura de segurança}

$\mathrm{Na}$ ótica da Organização de Aviação, implementar uma Cultura de Segurança significa manter o número de eventos, incidentes ou acidentes abaixo de um nível aceitável. Nenhum piloto quer ser interveniente em qualquer evento, incidente ou acidente. Este compromisso implica uma virtude profissional de disciplina e competência ao nível da atitude, dos conhecimentos e da sua aplicação.
A segurança tem um preço elevado, mas como bem realça uma frase emblemática nos Gabinetes de Segurança de Voo: 'se achas que a segurança é cara, experimenta o acidente'.

A cultura do erro é um pouco subjetiva, mas sabendo nós que errar é humano, há que aprender com os erros uns dos outros, quer pela análise dos acidentes e incidentes, quer pelo reporte voluntário das situações com impacto negativo na segurança.

\section{Cultura de reporte}

O reporte é uma mais-valia em todas as áreas profissionais. É a base de uma cultura informada e de aprendizagem, promovendo a alteração para melhor, requisito essencial para a segurança. Naturalmente, existem aspetos de confidencialidade e confiança no seu tratamento.

Transformar um bloco operatório num cockpit só faz sentido na perspetiva comportamental. $\mathrm{Na}$ verdade, estamos perante profissões muito diferentes, ambas altamente especializadas e apoiadas em tecnologia de topo, que em caso de erro colocam em risco a vida de pessoas.

A cultura de reporte assenta no princípio da não punição e na aprendizagem com os erros dos outros. $O$ erro é natural, o não reportar é intencional. Em aviação, se eu cometer um erro, ficarei feliz se mais ninguém o cometer, na sequência do meu reporte.

A nossa cultura latina inibe-nos muitas vezes de o fazer: tendemos a alinhar-nos na normalização do erro, contribuindo para o que conhecemos como condição latente, o que mais tarde ou mais cedo poderá resultar em incidente ou acidente, tornando-nos cúmplices do mesmo.

\section{O checklist}

Em aviação, o checklist é imprescindivel no combate ao erro, na gestão das interrupções e distrações, na divisão da carga de trabalho e prioridades, na resolução de conflitos e tomada de decisão, na adaptação rápida a novos procedimentos, na comunicação e assertividade interpessoal, na

1. Piloto de Linha Aérea e Responsável pelo CRM de todos os tripulantes. TAP. Lisboa. Portugal.

Recebido: 22 de Julho de 2014 - Aceite: 10 de Novembro de 2014 | Copyright $\odot$ Ordem dos Médicos 2014 
uniformização de procedimentos, numa melhor consciência situacional e supervisão mútua. ${ }^{2}$

O princípio e disciplina do checklist defende-nos das nossas fragilidades, tais como o esquecimento, cansaço, dúvidas, técnicas pessoais, entre outras. ${ }^{3}$ Contudo, só funciona com uma utilização disciplinada, isto é, não interessa apenas responder 'check', cumprindo a sua leitura e resposta, se não existir também a disciplina de confirmar antes de responder. $\mathrm{O}$ contrário de disciplina é a indisciplina, e a fronteira entre ambas assaz ténue, o que infelizmente explica muitos acidentes.

\section{A avaliação}

$\mathrm{Na}$ indústria da aviação o desempenho é regularmente objeto de Supervisão e Avaliação, o que nos obriga a uma atualização constante. Em linguagem de café, diria que todos nós ficamos satisfeitos quando a 'coisa' nos corre bem e não ficamos satisfeitos quando não corre e até sabemos porquê... Os pilotos, como os médicos, querem sempre que as 'coisas' corram bem.

Os pilotos submetem-se a avaliação várias vezes em cada ano, processo que deveria estar presente em todas as profissões. Neste mundo de direitos e deveres, todos ganharíamos com maior responsabilização no empenho e desempenho.

Por norma, não gostamos de ser avaliados. Todos temos fraquezas que evitamos expor. Contudo, não existindo avaliação acabamos por não nos empenhar tanto, criamos hábitos e esquecimentos devido a uma não atualização permanente.

As avaliações não deverão contudo ser aleatórias. É necessário que se desenrolem de forma honesta e identifiquem situações que originem o insucesso. Não assumir a existência de tais situações seria alinhar voluntariamente num erro organizacional, alimentando uma condição latente. Daí ser essencial o profissionalismo e isenção dos Avaliadores - pelo que estes, tal como os Instrutores, são igualmente avaliados nessa função.

A lógica das avaliações obedece a requisitos perfeitamente definidos. Em cada ano há lugar a refrescamento de conhecimentos teóricos e de sistemas do avião. A aprendizagem é posteriormente treinada em simulador e avaliada no ano seguinte. A par disso, a tal virtude da competência obriga-nos a um bom desempenho em todos os voos, e não apenas durante as verificações ou treinos.

\section{Factores humanos}

A comunicação entre os elementos da equipa, a chamada de atenção ou crítica, a gestão de conflitos, a liderança e o espírito de equipa são factores humanos essenciais na profissão de piloto - e em todas as outras - o problema da comunicação não advém do que se diz, mas sim de como se diz, onde se diz e à frente de quem se diz. Todos nós sabemos como não gostamos que falem connosco, é uma

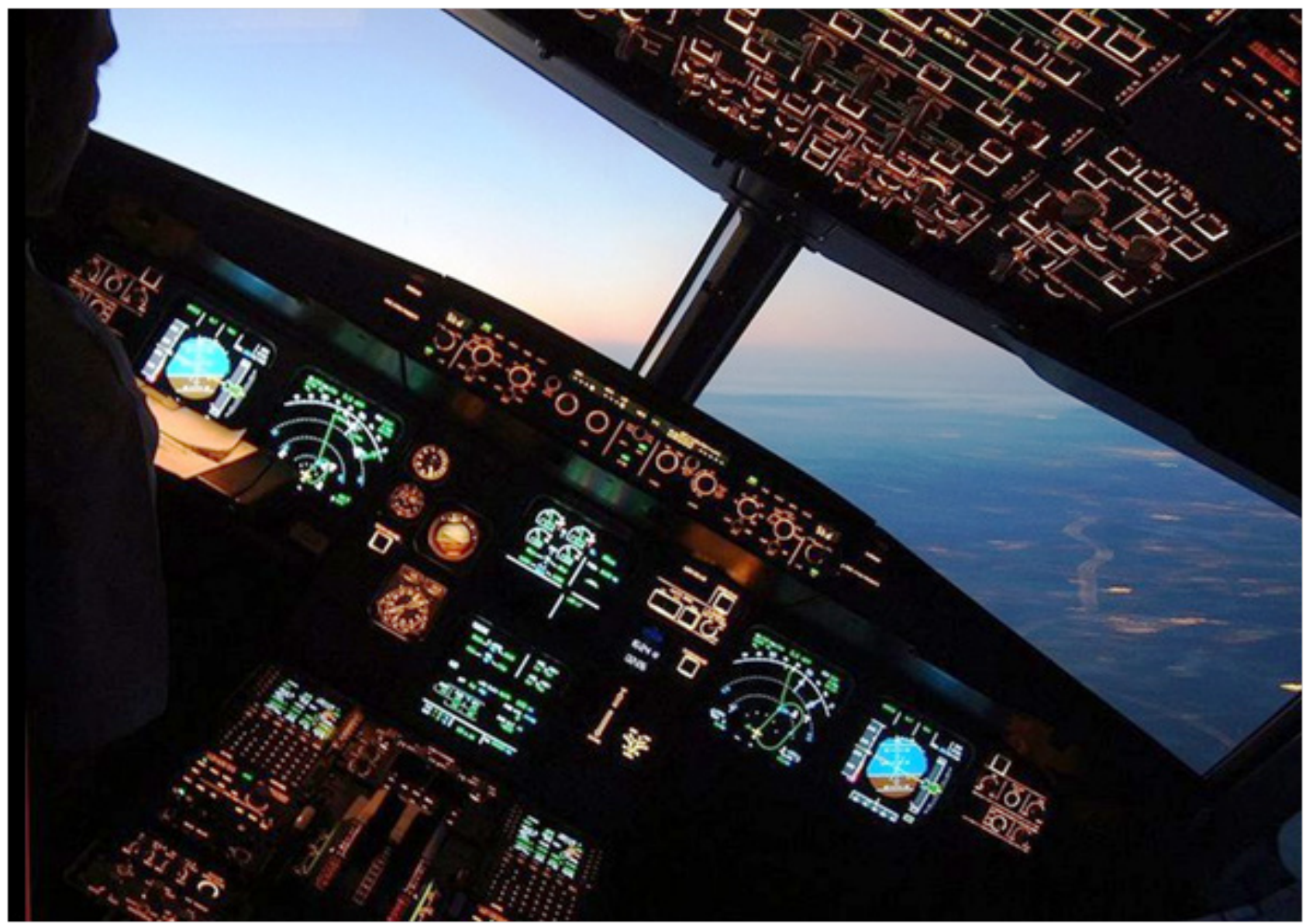

Figura 1 - Ambiente de cockpit 
questão de honestidade intelectual não o fazer aos outros. Comunicar de forma efetiva implica obrigatoriamente boa educação e respeito mútuo. Por exemplo, quando emitimos um reparo a alguém, deveremos fazê-lo de forma positiva, visando a melhoria. A crítica destrutiva, em oposição, é algo difícil de explicar e sem resultados.

Na gestão de conflitos, é importante diferenciar o conflito de ideias do conflito pessoal. Todos nós sabemos muito bem o que é colocar 'água na fervura' ou 'lenha na fogueira', mas muitas vezes acabamos por alinhar em situações que só criam desgaste, e ninguém lucra com isso. Estas situações em ambiente de cockpit são impensáveis e contraproducentes.

A gestão da carga de trabalho implica reconhecer que todos perdermos determinadas capacidades elementares sob cargas elevadas de trabalho. Deixamos, por exemplo, de prestar atenção a pormenores importantes, ou não ouvimos. Uma boa gestão deste aspecto passa por sabermos delegar correcta e atempadamente, gerir prioridades e praticar o que vulgarmente chamamos 'andar à frente do avião', ou seja, antecipar trabalho.

A liderança deve servir, em vez de exercer o poder. $O$ líder é só mais um elemento da equipa. Se assim se comportar, a equipa está com ele, caso contrário corre o risco de se ver sozinho num momento fundamental. Liderar implica gostar das pessoas e conhecê-las antes de as julgar.

A existência de dois pilotos no cockpit conduz à redundância, supervisão, assertividade e espirito de equipa, independentemente da experiência ou responsabilidade de cada um.

O briefing é a clarificação da estratégia de trabalho, contribui para não esquecermos nenhum detalhe na descolagem, aproximação ou aterragem, tanto em ambiente normal como em emergência, facilita a supervisão e a assertividade por parte do outro piloto quando algo sai do combinado.

O debriefing faz parte da cultura de reporte, neste caso verbal: no final de cada voo é importante haver uma autocrítica honesta, visando a aprendizagem e o reconhecimento do que poderia ter sido feito melhor. ${ }^{4,5}$

\section{A responsabilização}

É necessário compreender a cadeia do erro - onde residem alguns aspetos do foro intimo, já referidos, mas também outros externos como o Controlo de Tráfego Aéreo, a meteorologia, a legislação ou até a própria sorte ou azar. O que interessa compreender na cadeia do erro é que, por norma, somos o seu último elo. Dito de outra forma, o acidente evita-se devido à nossa atitude e profissionalismo.

A sociedade evoluiu para a necessidade da responsabilização. Cada vez mais é necessário identificar um culpado para os acidentes, existem pressões de vária ordem, provenientes dos familiares das vítimas, das apólices de seguros, dos operadores, dos fabricantes, da comunicação social, políticas ou outras, até da própria Lei do Estatuto do Comandante.

Este assunto é tratado através do conceito de "Just Cul- ture", nem sempre bem entendido, porque se o erro é bem aceite, e até aplaudido, quando reportado, a negligência ou violação grosseira não é tolerada, originando processos de inquérito ou disciplinares e dando inclusive lugar ao conceito de erro ou acidente organizacional. Não é aliás por acaso que surgem listas negras ou listagens das companhias mais seguras.

Todos nós vamos sendo confrontados com 'erros organizacionais'. Com a melhor das intenções alinhamos no 'empurrar com a barriga para a frente' e no 'isto ainda vai dar'. Em aviação, a falta de oposição a tal postura pode sair cara.

\section{Cockpit estéril}

O conceito de Cockpit estéril proíbe toda e qualquer comunicação que não esteja diretamente relacionada com as atividades em curso - abaixo de determinada altitude, a subir ou a descer - definindo claramente uma estratégia de concentração que evita as distrações nas fases críticas do voo.

A estatística indica que os acidentes acontecem sempre nas fases de rolagem, descolagem e na aproximação e aterragem - daí que nessas fases seja de promover a concentração nas atividades profissionais, sendo inoportuno debater temas corriqueiros. ${ }^{6}$

\section{A tripulação}

Uma das grandes diferenças entre a aviação e a medicina prende-se com a composição da equipa em cada voo. Em aviação, raramente as tripulações se repetem, o que sentimos como uma vantagem que combate a complacência. No cockpit - um espaço assaz limitado - a disposição ou atitude do piloto contagia facilmente o ambiente. Ao voar sempre com a mesma tripulação, encorajam-se rotinas que ao longo do tempo podem conduzir a um certo facilitismo e ao baixar das defesas, leia-se indisciplina, não compatível com o objetivo de tentar fazer sempre bem à primeira tentativa.

Outro especto diferente nas duas classes profissionais relaciona-se com os tempos de trabalho e gestão do descanso antes e depois dos voos, questões intimamente dependentes dos respetivos estilos de vida, independentemente do que esteja regulamentado. $\mathrm{Na}$ aviação, os limites de tempos de trabalho variam de acordo com alguns fatores, como a hora da apresentação, o número de aterragens e de pilotos, entre outros. Na medicina, os limites de tempos de trabalho encontram-se associados aos tempos de repouso, pelo que nem sempre a gestão do descanso se realiza de acordo com as normas recomendadas.

Em ambiente de aviação, a verificar-se desobediência às normas definidas, estaríamos a falar na aceitação do erro por rotina, em indisciplina, em falta de liderança, em erro organizacional, em condição latente, para só referir alguns aspectos que facilitam o erro ou, neste caso, violação grosseira. 


\section{AGRADECIMENTOS}

A Acta Médica Portuguesa agradece a colaboração e o modo gentil como foi recebida na visita ao Centro de Formação da TAP em particular a Armindo Martins, Eduardo Dinis e Ana Lúcia Lima.

\section{CONFLITOS DE INTERESSE}

$O$ autor declara não ter quaisquer conflitos de interesse relativamente ao presente artigo.

\section{FONTES DE FINANCIAMENTO}

Este trabalho não recebeu nenhuma contribuição de subsídio ou bolsa.

tion of current human factors approaches to patient handover. J Public Health Res. 2013;2:e33.

5. West P, Neily J, Warner L, Mills P, Mazzia L, Paull D, et al. Surgical programs in the Veterans Health Administration maintain briefing and debriefing following medical team training. Jt Comm J Qual Patient Saf. 2014;40:235-9.

6. Fore AM, Sculli GL, Albee D, Neily J. Improving patient safety using the sterile cockpit principle during medication administration: a collaborative, unit-based project. J Nurs Manag. 2013;21:106-11. 


\section{O Crew Resource Management como Contributo da Ciência Aeronáutica para a Ciência Médica}

Acta Med Port 2014:27:681-684

Publicado pela Acta Médica Portuguesa, a Revista Científica da Ordem dos Médicos

Av. Almirante Gago Coutinho, 151

1749-084 Lisboa, Portugal.

Tel: +351218428 215

E-mail: submissao@actamedicaportuguesa.com

www.actamedicaportuguesa.com

ISSN:0870-399X | e-ISSN: 1646-0758

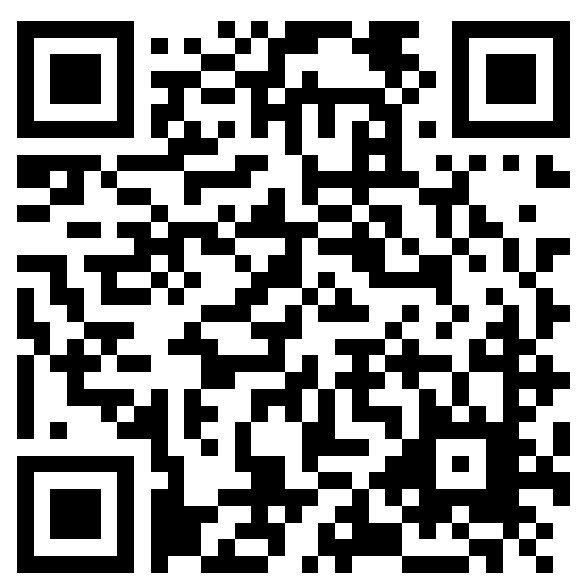

